\title{
Fishery Fee and Tax Rate in an Oligopoly Industry with Entry and Exit
}

\author{
Yu Shao, Kai Shen, Weiru Zhang, Shuntian Yao" \\ Division of Economics, Nanyang Technological University, Nanyang Ave, Singapore \\ Email: "\#080140@e.ntu.edu.sg
}

Received July 20, 2013; revised August 17, 2013; accepted August 24, 2013

Copyright (C) $2013 \mathrm{Yu}$ Shao et al. This is an open access article distributed under the Creative Commons Attribution License, which permits unrestricted use, distribution, and reproduction in any medium, provided the original work is properly cited.

\begin{abstract}
Over the last two decades, fisheries sector has been playing an important role in the global economy as a vibrant sector. By looking into the interactions among natural resources, human beings and government, this paper first briefly examines the issue of complicated conflicts in fisheries together with its influence on fisheries management. Under the assumption that the fishing resources will not be exhausted, this paper further reveals the particular conflicts between economic performance and community welfare by modelling the strategic interaction amongst the government and fishing firms based on the two stage non-cooperative game theory. With a dynamic model enclosed, this paper demonstrates with how the government establishes the fishing fee rate to achieve its primary goal and how the fishing firms react to the policy in each scenario. In the end, it concludes with some brief suggestions regarding policy-making for future work priorities. Although fishery industry is used as an example in this article, our main results, however, can be applied to any industries of oligopoly competitions with entry and exit.
\end{abstract}

Keywords: Fisheries Management; Fishing Fee; Non-Cooperative Game Theory; Entry and Exit; Optimal Tax Rate; Social Welfare

\section{Introduction}

As a sunrise sector of our economy, the fishery industry in China has emerged from a subsistence traditional activity into a government-controlled commercial enterprise. However, fishing conflicts are among the persistent problems due to its complex and dynamic bio-socio-economic system, with its many interactions among natural resources, human beings and government. Conflicts are broadly defined as a situation of non-cooperation between parties and contradictory objectives (FAO 1998) [1]. Conflicts in fisheries usually arise among stakeholders with differing economic and social motivations regarding the allocation and access rights to the limited natural resources.

Why are there conflicts in fisheries? There is a set of three fisheries "world views" which reflect the philosophical basis of fisheries conflicts. This framework was specified by Charles (1992) [2] to analyse the conflicts by introducing a trio of fishery paradigms, i.e. the conservation, rationalization, and social/community para-

*Each of the four authors has made equal contributions to this article.

${ }^{\#}$ Corresponding author. digms. Together the three paradigms form the corners of a "paradigm triangle" within which differing approaches to fisheries conflicts and policy problems can be analysed (see Figure 1).

Figure 1 features three philosophical paradigms and their unique policy objectives, which are:

- The conservation paradigm operates with a policy objective aimed at resource maintenance.

- The rationalization paradigm focuses on the pursuit of economic performance and productivity. That is, the government should centre on fishery fee maximization.

- The social paradigm emphasizes community welfare, equity of distribution, and other social and cultural fishery benefits, which takes into account of the total welfare of government plus the fishery firms.

Charles (1992) [2] enclosed three cases in his study to illustrate the framework of analysing conflicts. However, the hotspot discussed in academic field is about the conflicts between the conservation paradigm and the rationalization paradigm. Most of the coastal countries' policies are focusing on enhancing the community welfare while ensuring the sustainability of fishery resources. 


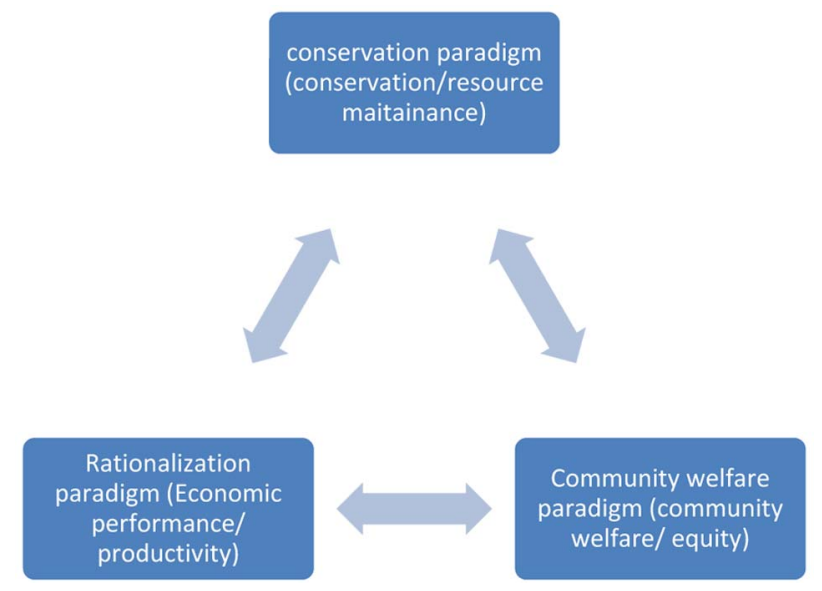

Figure 1. Framework for understanding and resolving conflicts in fisheries.

Those researches propose policy makers to adjust and control the fisheries by targeting on the total harvest amount. For example, Mainland Fisheries Authority of China imposed a two-month fishing moratorium in the South China Sea during Jun and July 1999 to preserve fishery resources (AFCD 1999) [3]; there are established systems of individual transferable quota (ITQ), which "gives fishers, vessels and/or producers dedicated access privileges to land a specified portion of total allowable catch (TAC)" and hundreds of fisheries globally is managed by this TAC-ITQ system (Chu, 2009) [4]. We therefore raise the interest of building a mathematical model to study the conflicts between the bottom two factors in Figure 1, namely the economic performance and community welfare.

In most of studies, conflicts are modelled by game theory. Essentially, it is a strategy that uses mathematics to describe player strategies in sources of conflict and common interest, and predicts what rational players should do, and not what they actually do (Luce \& Raiffa, 1957) [5].

We begin our review with the early principal-agent model developed by Clarke and Munro (1987) [6], in which a coastal nation imposes a fishing fee on a single distant water fishing nation (DWFN) which has the same rate of discount as it does. They (1991) [7] further generalize their first model by considering the possibility that the coastal nation and DWFN have different discount rates on future return from fishery. They find that the coastal nation can increase its discounted net return from the fishery by simultaneously using a tax on harvest and a tax on effort rather than only using one tax.

Raissi (2001) [8] examines a model in which uses a dual tax system with an inferior fishing technology on two fishing firms - a domestic firm and a foreign firm. Raissi demonstrates that if there is no regulation on fisheries then the foreign firm will eliminate domestic com- petition by exerting the maximum effort. However, it may be optimal if the coastal nation encourages the two firms to converge to the equilibrium at which they are both exploiting the fishery by using taxes. Neither Raissi (2001) [8] or Clarke and Munro (1987, 1991) [6,7] allow the coastal nation to choose the number of firms that operate in its fishery.

Additionally, some other authors use non-cooperative game theory to model the tactical interactions between firms in an international, unregulated fishery. Among those studies, Levhari and Mirman (1980) [9] and Fischer and Mirman (1996) [10] uses a utility maximization model while Dockner et al. (1989) [11] and Ruseski (1998) [12] uses a profit maximization model. They all conclude that the firms will over-fish the stock. Ruseski [12] shows that the respective government of each firm that competes over the fishery has the incentive to license more vessels than that at socially optimal level. The received revenue is used to subsidize its own firm's effort, which in turn exacerbates over-fishing.

Yoav Wachsman (2002) [13] develops a model to simulate interactions between coastal nation (principal) and foreign fishing firms (agents) by involving $\mathrm{n}$ firms into a 2-stage game. Besides, the study further reveals the conflicts between economic performance and social welfare, which means when government chooses to maximize its own profit it has to sacrifice the maximum level of total return of the principal-agents system as a whole. One of the significant contributions of this study is that it allows the number of firms to be a variable in the coastal nation's objective function. However, this solution is possible only based on the strong assumptions of identical firms and zero fixed costs so that the size of firm is allowed to be extremely tiny when number of firms goes to infinity. Nevertheless, this study is a unique approach to evolve previous 2-players or 2 groups-players game theory model.

Our paper is to provide a thoughtful advice on the fishery policy by simulating the dynamic process of market interactions and considering the full aspect of fishery paradigm triangle. Resource sustainability is set as a pre-requirement, and a proper tax rate is obtained by a compromise between economic performance and social welfare. Furthermore, the model is made to be more realistic by taking into account of the fixed cost of each individual firm. While we analyse the fishery industry as an example, our results actually applies to any oligopoly industries with entry and exit.

This paper is structured as follows: model description is presented first; followed by the mathematical analysis. Next, we simulate a simple case where firms have the same marginal cost of efforts and fixed costs, and supplemented by further discussion on social welfare prospect. Finally we conclude the paper with policy reviews for the governments. 


\section{Model Description}

In most of previous studies concerning resource constraint, Schaefer's Model (1957) [14] was used. In his model, harvest of each firm from the fishery can be calculated from a "catch per unit of effort (CPUE) product function". According to this function, each firm harvests a constant portion of the stock per unit of effort, $e_{i}$. Define $q_{i}$ as the quantity (harvest) for firm $i$. Consider the situation when the total harvest of $n$ existing firms $Q$ is less than the stock size $x$, i.e., $Q=\sum_{i=1}^{n} q_{i}<x$, each firm's harvest can be calculated as:

$$
q_{i}=l x e_{i}
$$

where $l$ is the catching ability coefficient, $0<l<1$. It was assumed that $l$ is independent from the stock size and it is identical for all the firms.

In a working paper written by Wachsman (2002) [13], the author proposed a fishery model based on Schaefer's Model. In Wachsman's Model [13], no fixed cost is assumed, and potentially it was assumed that the number of firms could tend to infinity.

The advantage of Wachsman's Model is that the constraint of the resource is explicitly modeled and discussed. The weakness of Wachsman's Model is that, the assumption of zero fixed costs does not really capture the reality of the fishery industry, and under such an assumption, entry into or exit from the industry cannot be discussed. Additionally, when the number of firms, $n$, becomes larger and larger, and tends to infinity eventually, the capacities of the firms must become smaller and smaller given the fixed amount of natural resource, this looks quite absurd.

Comparing to the Wachsman's study, this paper releases the zero-fixed-cost assumption and gives a snapshot of the dynamic process in the fishery industry. In this dynamic process of interaction, each individual firm would decide whether to continue operating under a specific tax rate imposed. A firm will quit once the after-tax profit turns negative.

In our model there are totally $N$ firms. Each firm $i$ has a marginal cost of $c_{i}$ and a fixed cost of $f_{i}$. The market inverse demand for the produce is given by

$$
P=a-Q
$$

where $Q$ is the total quantity supplied to the market and $P$ is the market clearing price. In addition to the production marginal costs as mentioned above, we also consider the tax rate $r$ against revenue imposed by the government.

The model is derived by backward induction. We start with solving the level of effort that each firm will select in the second stage. Subsequently we solve the optimal fishing tax rate $r$, which will maximize the government's tax revenue after computing the equilibrium quantity as a function of $r$.
We will not consider the resource constraint in the first place. Instead we will have a section to discuss it later.

\section{Mathematical Analysis}

Throughout our discussion, we will assume that any incumbent firm will not exit from the industry so long as its equilibrium profit is greater than or equal to zero, and we will also assume that any potential entrant will enter into the industry if it can get a nonnegative equilibrium profit after entry.

In our model firm i's profit function is expressed as:

$$
\pi_{i}=P Q-V C-F C=(1-r) \times P q_{i}-c_{i} q_{i}-f_{i}
$$

where $r$ is the tax rate that the government set, and $c_{i}, f_{i}$ are the marginal cost of quantity and fixed cost respectively for firm $i$. Therefore,

$$
\pi_{i}=(1-r)\left(a-\sum_{i=1}^{n} q_{i}\right) q_{i}-c_{i} q_{i}-f_{i}
$$

Notice that firm $i$ will continue to operate only if its profit is greater than or equal to zero.

For firm $i$, its objective function is

$$
\max _{q_{i}} \pi_{i}=(1-r)\left(a-q_{i}-\sum_{j \neq i}^{n} q_{j}\right) q_{i}-c_{i} q_{i}-f_{i}
$$

Rearrange firm i's profit function:

$$
\pi_{i}=(1-r)\left[-q_{i}^{2}+\left(a-\sum_{j \neq i}^{n} q_{j}\right) q_{i}\right]-c_{i} q_{i}-f_{i}
$$

Mathematically, when the first-order condition (F.O.C) with respect to $q_{i}$ of the profit function is satisfied, i.e. $\partial \pi_{i} / \partial q_{i}=0$, the corresponding quantity maximizes firm i's profit.

The first-order-condition of Equation (5) is

$$
2(1-r) q_{i}=(1-r)\left(a-\sum_{j \neq i} q_{j}\right)-c_{i}
$$

Subtracting $(1-r) q_{i}$ from both sides:

$$
(1-r) q_{i}=(1-r)(a-Q)-c_{i}
$$

Adding cross all firms:

$$
(1-r) Q=(1-r) n a-(1-r) n Q-\sum_{i=1}^{n} c_{i}
$$

therefore, we have:

$$
Q=\frac{(1-r) n a-\sum_{i=1}^{n} c_{i}}{(1-r)(n+1)}
$$

Substituting Equation (9) to Equation (7) and solve for $q_{i}$ :

$$
q_{i}=\frac{a}{n+1}+\frac{\sum_{j \neq i}^{n} c_{j}-n c_{i}}{(1-r)(n+1)}
$$

For our model, we assume that any firms stay in as far 
as the after-tax profit is greater than or equal to zero. With a process of a continuously increasing tax rate $r$, we assume that firms exits one by one. Let $n(r)$ be the number of firms remained in business for a given $r$.

In the first stage, government chooses a tax rate, $r$, to maximize the total amount of tax revenue received, $T$ :

$$
\max _{r} T(r)=r P Q
$$

Notice that there exists a supreme for all feasible $r$, noted by $r_{\text {sup }}$. It is the largest tax rate government could impose due to the limited fisheries stock. That is to say, any $r$ high than $r_{\text {sup }}$ is not feasible.

The following method can be used as a good approach for finding an optimal $r$.

Lemma 1: Assume that a group $S$ of existing firms can survive in the industry under a tax rate $r$ (i.e. each has a nonnegative equilibrium profit) when no entry occurs, then when the tax rate is reduced to $r^{\prime}<r$, these same group of firms can also survive.

Proof: We only need to show that, under the smaller tax rate, the new equilibrium profit for each firm increases.

Originally, the profit function for firm $i$ is

$$
\pi_{i}=(1-r) \times(a-Q) q_{i}-c_{i} q_{i}-f_{i}
$$

Substitute Equations (9) and (10) into Equation (12) and simplify:

$$
\pi_{i}=\frac{1}{(n+1)^{2}}\left[(1-r) a^{2}+2 a b+\frac{b^{2}}{1-r}\right]-f_{i}
$$

where $b=\sum_{j \neq i}^{n} c_{j}-n c_{i}$, approximately equals $c_{i}$.

At the critical point that firm $i$ could survive, its profit equals to zero. Set Equation (13) equals to zero, we will get two solutions of $r$. In this case, we choose the smaller $r$ because beyond this $r$ firm $i$ has already decided to quit the industry and the larger $r$ is not feasible.

Take first-order derivative of Equation (13), we have:

$$
\frac{\partial \pi_{i}}{\partial r}=-\frac{a^{2}}{(n+1)^{2}}+\frac{b^{2}}{(n+1)^{2}(1-r)^{2}}
$$

Equivalently:

$$
\frac{\partial \pi_{i}}{\partial r}=-\frac{[a(1-r)-b][a(1-r)+b]}{(n+1)^{2}(1-r)^{2}}
$$

In this function, $a$ denotes the maximum price determined by supply-demand mechanism and $b$ is approximately equals to firm i's marginal cost. Since firm $i$ can survive at given $r$, its unit after-tax revenue $(1-r) a$ should be able to at least cover its marginal cost, $b$, and fixed cost per unit. Explicitly, $(1-r) a-b>0$ Thus $\partial \pi_{i} / \partial r<0$ at $r$. In addition, from Equation (14) we know that when $r$ decreases, $\partial \pi_{i} / \partial r$ also decreases. Therefore the derivative is negative for a given $\mathrm{n}$ on
$[0, r)$. By First Derivative Test, $\pi_{i}$ is decreasing on $[0, r)$. Therefore, under the smaller tax rate, $r^{\prime}$, the new equilibrium profit for each firm will be larger. To be exact, the same group of firms will remain survivable.

Let $N$ be the number of all potential firms in fishery industry. Now let us consider all possible nonempty subset of the set of $N$ firms. There are $2^{N}-1$ of these subsets.

Definition: A subset $S$ of firms is said to be coexistible if there exists a tax rate $r \geq 0$ under which each member in $S$ earns a nonnegative profit and no entry will occur in the industry.

Now let us discuss the situations for coexistable subsets. Obviously the number of coexistible subsets of $N$ is finite.

Lemma 2: For any coexistiblesubset $S$ of firms, there must exist a maximal tax rate $r_{h}(S) \geq 0$ such that under this tax rate $S$ remains coexistible and at least one member in $S$ has 0 equilibrium profit.

Proof: Because $S$ is coexistible, there is a tax rate $r \geq 0$ under which each member in $S$ earns nonnegative profit and no entry occurs in the industry. When the tax rate increases, by Lemma 1 no entry can occur, and at the same time the profit of each of the existing firm is reduced gradually. Note that each existing firm's profit depends on $r$ continuously, and as a result the smallest profit among them also continuously depends on $r$. The smallest profit is negative when $r$ is increased to 1 , by continuity there must exist some tax rate $r_{h}(S) \geq 0$ making this smallest profit exactly equal to 0 .

Lemma 3: For any coexistible subset $S$ of firms, either there exist some $r_{l}(S) \geq 0$ such that entry into the industry will start to occur under this tax rate, or entry never occurs even the tax rate is reduced to 0 .

Proof: The argument is trivial.

Let $S$ be a coexistible subset of firms. Now we consider two different cases in Lemma 3.

Case 1: Suppose entry will occur when tax rate is reduced to $r_{l}(S)$.

The tax revenue $T(S, r)$ for the government from these firms is continuously dependent on $r$ in the interval on $\left(r_{l}(S), r_{h}(S)\right]$. In this interval, there is a least upper bound on government revenue. If it can be attained at some $r$-value $r^{*}(S)$ within the half open interval, we will denote it $T^{*}(S)$; if it is cannot attained within this interval, we define:

$$
\tilde{T}(S)=\lim _{r \rightarrow r_{l}(S)+} T(S, r)=T\left(S, r_{l}(S)^{+}\right)
$$

Note that $\tilde{T}(S)$ cannot be precisely achieved, but can be approximately achieved as $r$ is reduced to sufficiently closed to but not equal to $r_{l}(S)$.

Case 2: entry will never occur

When $r$ varies from 0 to $r_{h}(S)$, the firms in $S$ are always coexistible. Again we use $T^{*}(S)$. 
Denote $T^{\sim}(S)$ to be either $T^{*}(S)$ or $\tilde{T}(S)$. As there are at most $2^{N}-1$ coexistible subsets, which is finite, $\left\{T^{\sim}(S): S \subseteq N\right\}$ has finite elements. Therefore, a maximum value among all the elements $T^{M}$ exists as either a maximum value achievable or a supremum.

To sum up we have

Proposition 1: For each subset $S$ of coexistible firms, let $r^{\sim}(S)$ be $r^{*}(S)$ or $r_{l}(S)$, dependent on whether or not the maximum of $T(S)$ can be achieved within $\left(r_{l}(S), r_{h}(S)\right]$. Let $T^{\sim}(S)$ to be either $T^{*}(S)$ or $\tilde{T}(S)$. Let $T^{M}=\max _{s}\left\{T^{\sim}(S)\right\}$. Then $T^{M}$ is either the maximum revenue achievable, or is the least upper bound.

\section{Numerical Examples}

To better illustrate the optimization process on government's decisions, we give a simple example with all firms to be identical.

Suppose there are 5 potential firms in total in the industry, i.e. $N=5$.

We randomly assign the values for parameters as follows:

\begin{tabular}{cccc}
\hline $\boldsymbol{a}$ & $\boldsymbol{c}$ & $\boldsymbol{f}$ & $\boldsymbol{N}$ \\
\hline 7 & 1 & 2 & 5 \\
\hline
\end{tabular}

As all firms are identical, all subsets of $n$ firms, denoted by $S_{n}$, are exactly the same combination as long as nis fixed. We can simplify Equation (13) into

$$
\pi_{i}=\frac{1}{(n+1)^{2}}\left[(1-r) a^{2}-2 a c+\frac{c^{2}}{1-r}\right]-f
$$

Substitute the values into above equation:

$$
\pi_{i}=\frac{1}{(n+1)^{2}}\left[49(1-r)-14+\frac{1}{1-r}\right]-2
$$

when $r=0, n=5$, we get $\pi_{i}=-1<0$; i.e. the subset consisting all 5 firms is non-coexistible.

When $r=0, n=4$, we get $\pi_{i}=-0.56<0$; i.e. the subset consisting 4 firms is non-coexistible.

When $r=0, n=3$, we get $\pi_{i}=0.25>0$; i.e. the subset consisting 3 or less firms are coexistible

For subset $S_{3}$ consist of 3 firms operating in the indus- try, to find $r_{h}\left(S_{3}\right)$, we set $\pi_{i}=0$ for Equation (17). Solving the equation gives us $r_{h}\left(S_{3}\right)=8.35 \%$. When $r$ decreases from $8.35 \%$ to 0 , no entry will occur.

Government's Revenue Function is:

$$
T_{r}=r P Q=r(a-Q) Q
$$

Substitute Equation (9) into Equation (18):

$$
\begin{aligned}
T(r) & =\frac{n r}{(n+1)^{2}}\left(a+\frac{n c}{1-r}\right)\left(a-\frac{c}{1-r}\right) \\
& =\frac{3 r}{16}\left(7+\frac{3}{1-r}\right)\left(7-\frac{1}{1-r}\right)
\end{aligned}
$$

Take the first-order derivative of Equation (19):

$$
\frac{\partial T}{\partial r}=\frac{147}{16}+\frac{33-51 r}{16(1-r)^{3}}
$$

Take the second-order derivative of Equation (19):

$$
\frac{\partial^{2} T}{\partial r^{2}}=\frac{768-1632 r}{256(1-r)^{4}}>0 \text { for } r \in[0,0.0835]
$$

By first-order derivative test, $\partial T / \partial r$ is increasing for $r \in[0,0.0835]$. Thus

$\partial T / \partial r>\partial T /\left.\partial r\right|_{r=0}=18$ for $r \in[0,0.0835]$. Therefore $T$ is an increasing function on $r \in[0,0.0835]$. So we have $T^{*}\left(S_{3}\right)=T(0.0835)=0.950$.

We continue to solve the cases with subset $S_{2}$ and $S_{1}$ by similar methods and the results are shown in Table 1:

We plot $T\left(S_{n}\right)$ against $r$ for $n=1,2$ and 3, as shown in Figure 2.

The result shows that government can achieve the maximum revenue of 6.426 by imposing a revenue tax at the rate of $60.23 \%$ and when only one firm remaining in the industry.

\section{Social Welfare Perspective}

The total profit earned by the firms can be obtained by summing Equation (12) across the $n$ existing firms, which is $(1-r)(a-Q) \sum_{i=1}^{n} q_{i}-\sum_{i=1}^{n} c_{i} q_{i}-\sum_{i=1}^{n} f_{i}$, where $Q$ is the total harvest of all existing firms. Then the government's revenue is $r(a-Q) \sum_{i=1}^{n} q_{i}$. Define $W$ as the net return from the entire fishery industry that is the summation of total profit from all the firms and the

Table 1. Calculations results 1.

\begin{tabular}{lccccc}
\hline & $r_{l}(S)$ & $r_{h}(S)$ & $r^{*}(S)$ & $T^{*}(S)$ & $\tilde{T}(S)$ \\
\hline S5 & & Non-coexistible & & \\
S4 & & Non-coexistible & & - \\
S3 & 0 & $8.35 \%$ & $8.35 \%$ & 0.950 & - \\
S2 & $8.35 \%$ & $37.98 \%$ & $37.98 \%$ & 4.649 & - \\
S1 & $37.98 \%$ & $60.23 \%$ & $60.23 \%$ & 6.426 & - \\
\hline
\end{tabular}




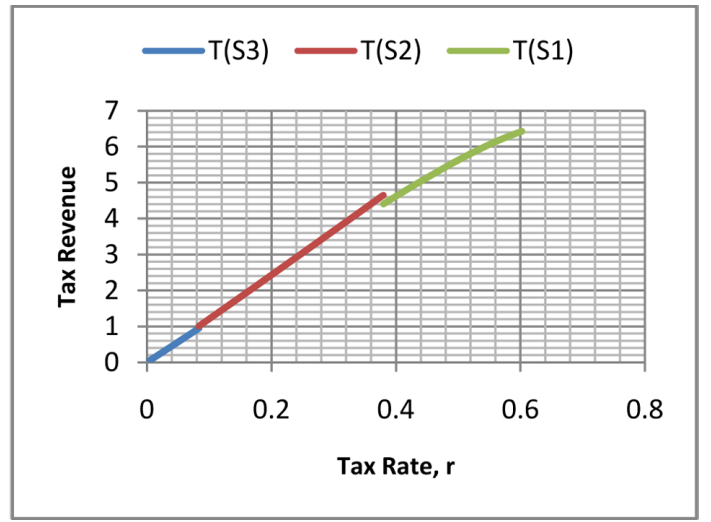

Figure 2. Tax Revenue against Tax Rate.

government's revenue, i.e.:

$$
W(r)=(a-Q) \sum_{i=1}^{n} q_{i}-\sum_{i=1}^{n} c_{i} q_{i}-\sum_{i=1}^{n} f_{i}
$$

Instead of achieving maximum revenue, government can also set tax rate $r$ targeting to maximizing social welfare. The process of determining this $r$ can follow the same method of finding the tax revenue maximization tax rate.

For each $S$ of coexistible firms, consider welfare $W(r)$ when $r$ varies in $\left(r_{l}(S), r_{h}(S)\right]$. Either the maximum $W^{*}(S)$ is attained within the interval at some $r_{W}{ }^{*}(S)$, or the supremum $\tilde{W}^{*}(S)$ is achieved as $r$ tends to $r_{l}(S)$ from the right. Very much similar to the arguments for Proposition 1, we have

Proposition 2: For each subset $S$ of coexistible firms, let $r^{\wedge}(S)$ be $r_{W}{ }^{*}(S)$ or $r_{l}(S)$, dependent on whether or not the maximum social welfare of $W(S)$ can be achieved within $\left(r_{l}(S), r_{h}(S)\right]$. Let $W^{\sim}(S)$ to be either $W^{*}(S)$ or $W(S)$. Let $W^{M}=\max _{s}\left\{W^{\sim}(S)\right\}$. Then $\mathrm{W}^{M}$ is either the maximum social welfare achievable, or is the least upper bound.

In the example of identical firms above, substitute Equations (9) and (10) into Equation (22), we get the welfare function when all firms are identical:

$$
\begin{aligned}
W(r)= & \frac{n}{(n+1)^{2}}\left[(1-r) a^{2}-2 a c+\frac{c^{2}}{(1-r)}\right. \\
& \left.+r\left(a+\frac{n c}{1-r}\right)\left(a-\frac{c}{1-r}\right)\right]-n f
\end{aligned}
$$

Plot $W\left(S_{n}\right)$ against $r$ for $n=1,2$ and 3 .

Figure 3 shows that when government imposes a tax rate larger than but extremely close to $r_{l}\left(S_{3}\right)=37.98 \%$, the social welfare can be ultimately close the maximum value. Yet this maximum value can never be exactly achieved. However, this preferred tax rate is clearly different with the tax rate that achieving $T^{M}$, which is $53.18 \%$.

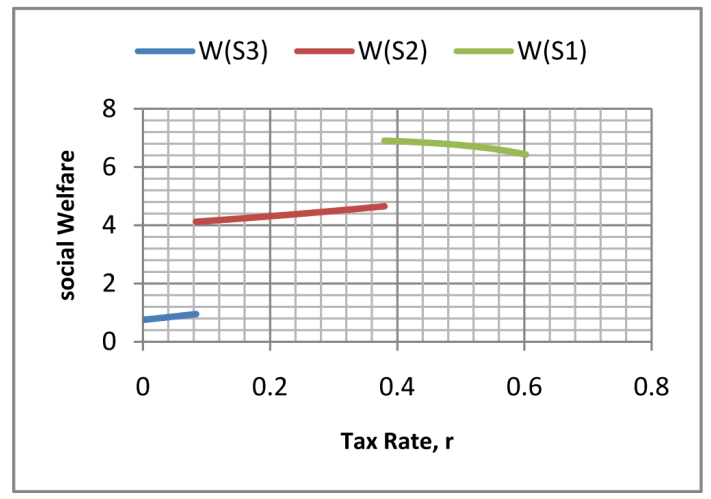

Figure 3. Social Welfare against Tax Rate.

In above example, we notice that social welfare is maximized when the firm is operating as a monopolist. This may due to a relative large fixed cost compare to the demand. Explicitly speaking, when firm quits with an increasing tax rate, the increase in demand is less than the decrease in total fixed costs; and hence the total return from the entire industry increases. Next we reduce the fixed cost of each firm to 0.7 to see whether social welfare will still be maximized in monopoly market.

In a new example, the parameters have following values:

\begin{tabular}{cccc}
\hline $\mathbf{a}$ & $\mathbf{c}$ & $\mathbf{f}$ & $\mathbf{N}$ \\
7 & 1 & 0.7 & 5 \\
\hline
\end{tabular}

Calculation results are listed in Table 2 below:

Figure 4 plots both tax revenue and social welfare against rate.

In this example, social welfare is maximized in duopoly market with a tax rate of $60.01 \%$; while the maximum tax revenue, 7.56 , is achieved when the tax rate is $64.28 \%$ and 2 firms remain in the industry. Again, the two goals are achieved at different tax rate.

Generally speaking, government can target to either maximize its revenue $T$ or social welfare $W$ but hardly to achieve both of them simultaneously.

\section{Taxation as a Measure for Protection of Resource}

In the above discussion so far we did not directly consider the resource constraint, and when social welfare was considered, it's the one period welfare. In the long term an economy may also need to consider resource protection. Fortunately in our model, the government could use taxation to control the total amount of resource being consumed.

Actually it is easy to see that, when the tax rate is increased, the total amount $Q$ harvested is reduced, as is stated in. 
Table 2. Calculation results $2^{3}$.

\begin{tabular}{lcccccccc}
\hline & $r_{l}(S)$ & $r_{h}(S)$ & $r^{*}(S)$ & $T^{*}(S)$ & $\tilde{T}(S)$ & $r_{w}{ }^{*}(S)$ & $W^{*}(S)$ & $\tilde{W}(S)$ \\
\hline S5 & 0 & $22.61 \%$ & $22.61 \%$ & 2.413 & - & $22.61 \%$ & 2.415 & - \\
S4 & $22.61 \%$ & $39.06 \%$ & $39.06 \%$ & 4.543 & - & $39.06 \%$ & 4.543 & - \\
S3 & $39.06 \%$ & $52.90 \%$ & $52.90 \%$ & 6.467 & - & $52.90 \%$ & 6.467 & - \\
S2 & $52.90 \%$ & $64.28 \%$ & $64.28 \%$ & 7.560 & - & $60.01 \%$ & 7.600 & - \\
S1 & $64.28 \%$ & $73.37 \%$ & $67.59 \%$ & 6.671 & - & $64.28 \%$ & - & 7.49 \\
\hline
\end{tabular}

${ }^{3} r_{T}^{*}(S)$ denotes the tax rate that maximizes tax revenue and $r_{W}{ }^{*}(S)$ represents the tax rate that maximizes social welfare. $T^{*}(S)$ (or $\left.W^{*}(S)\right)$ is the maximum tax revenue (or social welfare) when it can be exactly achieved and $\tilde{R}(S)$ (or $\tilde{W}(S)$ ) is the supreme of tax revenue (or social welfare) when it cannot be exactly achieve.

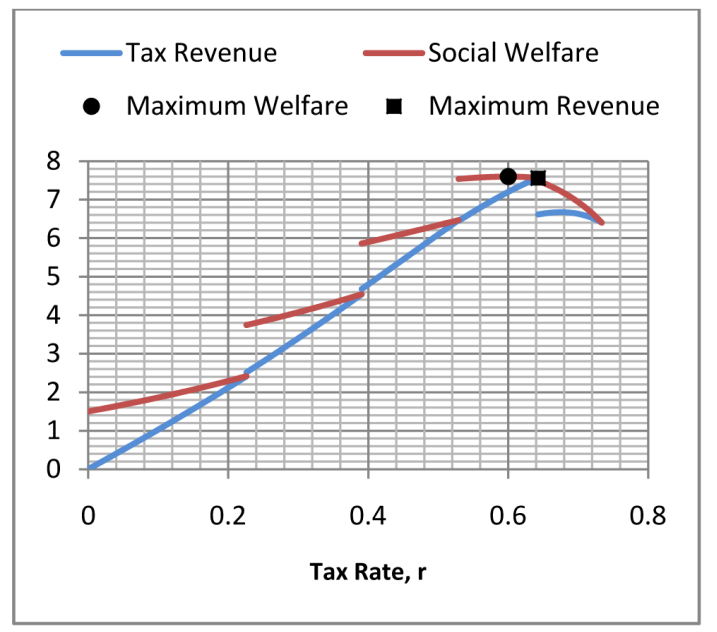

Figure 4. Revenue and Social Welfare against Tax Rate.

Proposition 3: For any coexistible subset $S$ of firms, as the tax rate $r$ increases, the total quantity harvested $Q$ is reduced.

Proof: Rewriting Equation (9):

$$
Q=\frac{n a}{(n+1)}-\frac{\sum_{i=1}^{n} c_{i}}{(1-r)(n+1)}
$$

Note that, when $r$ increases, the second term in the right-hand side has a larger absolute value, and as a result $Q$ is smaller.

Remark: While the proof of Proposition 3 is easy, the result is not completely trivial. From equation (10), it is interesting to note that, when the firms are asymmetric, the firm with the smallest marginal cost might increase its output when the tax rate $r$ increases, yet the industry total output is always reduced. This is an important feature for an oligopoly industry.

It can be better illustrated with the following example.

To be consistent, we again assume that there are 5 firms in the market and keep $a=7$. However, now the firms are asymmetric, their marginal costs and fixed costs differ with each other. They are listed as follows:

\begin{tabular}{cccccc}
\hline$i$ & 1 & 2 & 3 & 4 & 5 \\
$c_{i}$ & 0.5 & 1.2 & 1 & 0.9 & 1.1 \\
$f_{i}$ & 2 & 0.4 & 0.6 & 0.7 & 0.5 \\
\hline
\end{tabular}

Note that firm 1 is the leading firm in the market, which has the smallest marginal cost.

Set tax rate $r$ as $8 \%$. We calculate each firm's harvest according to Equation (10):

\begin{tabular}{cccccc}
\hline$q_{1}$ & $q_{2}$ & $q_{3}$ & $q_{4}$ & $q_{5}$ & Total $(Q)$ \\
1.47 & 0.71 & 0.93 & 1.04 & 0.82 & 4.98 \\
\hline
\end{tabular}

Now we assume the tax rate increases to $10 \%$. The harvest of each firm becomes:

\begin{tabular}{cccccc}
\hline$q_{1}$ & $q_{2}$ & $q_{3}$ & $q_{4}$ & $q_{5}$ & Total $(Q)$ \\
1.48 & 0.70 & 0.93 & 1.04 & 0.81 & 4.96 \\
\hline
\end{tabular}

In this example, we can see that with tax rate increasing from $8 \%$ to $10 \%$, although the total production dropped by 0.02 , firm 1 's individual harvest raised from 1.47 to 1.48 . This is a noteworthy feature of an oligopoly market with the presence of a leading firm. In fact we can state a general result:

Proposition 4: In an oligopoly industry with $n$ firms, as the corporate tax rate $r$ increases, any member with its marginal cost less than $n /(n+1)$ of the average marginal cost will increase its output.

Proof: Let $c$ be the average marginal cost: $c=\frac{1}{n} \sum_{j=1}^{n} c_{j}$. Suppose for firm $i$ it holds that $c_{i}<\frac{n c}{n+1}=\sum_{j=1}^{n} \frac{c_{j}}{n+1}$. This is equivalent to $(n+1) c_{i}<\sum_{j=1}^{n} c_{j}$, or $n c_{i}<\sum_{j \neq i} c_{j}$.

Recall Equation (10):

$$
q_{i}=\frac{a}{n+1}+\frac{\sum_{j \neq i}^{n} c_{j}-n c_{i}}{(1-r)(n+1)}
$$


Now the second term in the right-hand side is positive, and as $r$ increases its value increases.

In view of Proposition 3, for resource protection the government could always choose a tax rate making sure the total resource consumed does not exceed some upper bound. With this additional constraint the government could redo the calculations, discovering an optimal tax rate to maximize the per-period social welfare and at the same time protecting the resource for long term consumption. In view of Proposition 4, increasing tax rate in the long run will force firms with backward technology (with higher MC) to exist and encourage firms with more advanced technology (with lower MC) to enter.

\section{Conclusions}

Throughout the paper, non-cooperative game theory is used to model the strategic interactions between fishery firms and the government.

We construct a dynamic model in which different marginal costs and fixed costs are applied to different firms respectively. In this dynamic model, with a specified tax rate, firms may earn negative profits due to the presence of fixed costs. Hence it may choose to retire from fishery. Government will revise the tax rate according to its goal because of the changes in the number of firms and the existing firms' strategies. New tax rate will induce firms' new decisions. The iteration will go on until equilibrium achieved when government accomplishes its goal and no existing firms chooses to quit. The dynamics in this model makes the government revenue and net return are not always continuous in $r$ (tax rate). However, we can determine the optimal $r$ by a discrete optimization process. We assert that government can set a tax rate either to achieve (or to be infinitely closed to) the maximum revenue or to achieve (or to be infinitely closed to) the social welfare maxima. It is hard to find a single tax rate that can achieve both goals simultaneously. Moreover, taxation on fishing firms' revenues can be used as a tool for protecting fishing resources. When government increases tax rate, the total production will always reduce. One interesting point to note here is that, even though the total production reduces, the leading firm with the smallest marginal cost in an oligopoly market might still increase its production.

Based on the model constructed, the existence of fishery conflicts paradigm is revealed automatically. Nowadays, because of the upsurge discussion on environmental sustainability among the public, policy makers pay most of their attention to resource maintenance. However, conflicts are prevalent because of the poor implementation and enforcement of most fishery laws and regulations. Thus, it is necessary to involve all stakeholders in the fishery industry and related sectors as well as the policy makers and fisheries managers in a thorough and periodic review of policies and institutions. This paper suggests that future policy making should take into account of thorough argumentation in favor of the necessity not only to maintain the natural resources but also to increase yields and social welfare in future.

\section{REFERENCES}

[1] Food and Agriculture Organization of the United Nations, "Integrated Coastal Area Management and Agriculture, Forestry and Fisheries," FAO Guidelines, Rome, 1998.

[2] A. T. Charles, "Fishery Conflicts: A United Framework," Marine Policy, Vol. 16, No. 5, 1992, pp. 379-393. doi:10.1016/0308-597X(92)90006-B

[3] Agriculture, Fisheries and Conservation Department, "Hong Kong Annual Report 1999," 1999. http://www.yearbook.gov.hk/1999/eng/08/08_00.htm

[4] C. Chu, "Thirty Years Later: The Global Growth of ITQs and Their Influence on Stock Status in Marine Fisheries," Fish and Fisheries, Vol. 10, No. 2, 2009, pp. 217-230. doi:10.1111/j.1467-2979.2008.00313.x

[5] D. R. Luce and H. Raiffa, "Games and Decisions: Introduction and Critical Survey," Wiley, New York, 1957.

[6] F. H. Clarke and G. R. Munro, "Coastal States, Distant Water Fishing Nations and Extended Jurisdiction: A Principal-Agent Analysis," Natural Resource Modeling, Vol. 2, No. 1, 1987, pp. 81-107.

[7] F. H. Clarke and G. R. Munro, "Coastal States and Distant Water Fishing Nations: Conflicting Views of the Future," Natural Resource Modeling, Vol. 5, No. 3, 1991, pp. 534-569.

[8] N. Raissi, "Features of Bioeconomics Models for the Optimal Management of a Fishery Exploited by Two Different Fleets," Natural Resource Modeling, Vol. 14, No. 2, 2001, pp. 287-310.

doi:10.1111/j.1939-7445.2001.tb00060.x

[9] D. Levhari and L. J. Mirman, "The Great Fish War: An Example Using a Dynamic Cournot-Nash Solution," Bell Journal of Economics, Vol. 11, No. 1, 1980, pp. 322-334. doi: $10.2307 / 3003416$

[10] R. D. Fischer and L. J. Mirman, "The Compleat Fish Wars: Biological and Dynamic Interactions," Journal of Environmental Economics and Management, Vol. 30. No. 1, 1996, pp. 34-42. doi:10.1006/jeem.1996.0003

[11] E. Dockner, G. Feichtinger and A. Mehlmann, "NonCooperative Solutions for a Differential Game Model of Fishery," Journal of Economic Dynamics and Control, Vol. 13, No. 1, 1989, pp. 1-20. doi:10.1016/0165-1889(89)90008-0

[12] G. Ruseski, "International Fish Wars: The Strategic Roles for Fleet Licensing and Effort Subsidies," Journal of Environmental Economics and Management, Vol. 36, No. 1, 1998, pp. 70-88. doi:10.1006/jeem. 1998.1038

[13] Y. Wachsman, "A Model of Fishing Conflicts in Foreign Fisheries," Working Paper No.02-16, 2002.

[14] M. B. Schaefer, "Some Considerations of Population Dynamics and Economics in Relation to the Management of 
Marine Fisheries," Journal of Fisheries Research Board of Canada, Vol. 14, 1957, pp. 669-681. doi:10.1139/f57-025 